\title{
Q9.
}

José Carlos García de Quevedo Ruiz*

\section{FINANZAS E INVERSIONES SOSTENIBLES La sostenibilidad en ICO}

La sostenibilidad constituye un reto multidimensional, sintetizado a través de los Objetivos de Desarrollo Sostenible, la Agenda del Cambio y el Pacto Verde Europeo, cuya consecución requiere de una gran inversión de recursos. En este proceso el sector financiero debe jugar un papel clave desarrollando un modelo de finanzas sostenibles que incentive la incorporación de los objetivos medioambientales, sociales y de gobernanza en las decisiones empresariales, movilizando recursos en la escala y el plazo necesarios para facilitar la transición hacia un modelo de crecimiento sostenible bajo en emisiones. Mediante su Reorientación Estratégica 20192021, Grupo ICO sitúa la sostenibilidad como un principio horizontal de actuación, involucrando a toda la organización, tanto en operaciones de pasivo, con papel destacado en el desarrollo de mercado de bonos sostenibles en Europa, como en operaciones de activo, canalizando recursos hacia proyectos sostenibles de emprendedores, autónomos, pymes y grandes empresas. La sostenibilidad es, asimismo, un principio esencial de su política de responsabilidad social empresarial, tanto a nivel interno como externo, impulsando iniciativas y principios de actuación a nivel nacional e internacional, con el objetivo de crear un marco común de estándares y reglas para coordinar esfuerzos, identificando y financiando proyectos sostenibles.

Palabras clave: responsabilidad social, ODS, pymes, private equity, venture capital.

Clasificación JEL: E58, K32, M14.

\section{Sostenibilidad: ODS y cambio climático}

La sostenibilidad constituye un reto multidimensional y complejo, sintetizado a través de

\footnotetext{
* Presidente de ICO, Técnico Comercial y Economista del Estado. Siendo la sostenibilidad una dimensión transversal en las organizaciones y actividades, este articulo ha sido elaborado con la contribución de todas las Direcciones Generales del Instituto y con la especial dedicación de Alfonso Noriega y Begoña Amores, de la Dirección de Relaciones Institucionales y Comunicación.

Versión de enero de 2020.

DOI: https://doi.org/10.32796/bice.2020.3120.6971
}

los Objetivos de Desarrollo Sostenible, el Pacto Verde Europeo y la Agenda del Cambio, cuya consecución requiere de una gran movilización de recursos, inversiones y desinversiones a la vez que se promueve una transición energética y ecológica justa.

En este proceso el sector financiero debe jugar un papel clave desarrollando un modelo de finanzas sostenibles, aún incipiente pero en destacada progresión, que genere incentivos para incorporar los objetivos medioambientales, sociales y de gobernanza en las $D$ 
decisiones empresariales, movilizando recursos en la escala y el plazo necesario para facilitar la transición hacia un modelo de crecimiento sostenible bajo en emisiones.

\subsection{El alcance de la sostenibilidad}

La sostenibilidad es un concepto complejo y multidimensional, que engloba aspectos medioambientales, sociales y de gobierno corporativo ( $E S G^{1}$ por sus siglas en inglés). En el marco de Naciones Unidas se ha sintetizado el concepto de sostenibilidad a través de la Agenda 2030 y sus diecisiete Objetivos de Desarrollo Sostenible, estableciendo un marco para la coordinación internacional en la promoción de objetivos interrelacionados como el trabajo decente, el crecimiento económico, la acción por el clima, la producción y el consumo responsables, la innovación o la vida submarina.

De forma reciente, durante la celebración en diciembre de 2019 de la COP25² en Madrid, se ha hecho especial énfasis en la importancia de la consecución del ODS13 «Acción por el clima», que recoge en su seno los Acuerdos de París de 2015, orientados a moderar el crecimiento medio de la temperatura del planeta por debajo de $2^{\circ} \mathrm{C}$ con respecto a los niveles preindustriales, mediante la asunción de compromisos de reducción

1 ESG:

- Environment (medio ambiente): cambio climático, emisiones GEI, agotamiento de recursos, residuos.

- Social: condiciones laborales, salud y seguridad, relaciones con empleados y diversidad, comunidades locales.

- Governance (gobierno corporativo): compensación de ejecutivos, corrupción, diversidad de los órganos directivos, fiscalidad.

2 Conferencia de las Partes, órgano de decisión supremo de la Convención Marco de la ONU sobre Cambio Climático (UNFCCC), establecida en 1992 y reunida por primera vez en 1995. Junto a la falta de compromiso de EE UU, China, Rusia e India (suman más del $55 \%$ de las emisiones de $\mathrm{CO}_{2}$ ), en COP25 no se han logrado alcanzar los objetivos de aumento generalizado del nivel de ambición de los NDC ni el establecimiento de un mercado mundial de emisiones de dióxido de carbono planteado en el artículo 6 del Acuerdo de París (https://www.lamoncloa.gob.es/servicios deprensa/notasprensa/ecologica/Paginas/2019/151219cop25.aspx). de emisiones de gases de efecto invernadero por parte de los países firmantes. Estos compromisos se reflejan en los National Determined Contributions (NDC) ${ }^{3}$, plasmados a su vez en los respectivos Planes Nacionales de Energía y Clima, que incluyen una serie de medidas e inversiones de eficiencia energética, generación mediante energías renovables y electrificación de la economía, estando por tanto íntimamente relacionados con otros objetivos como ODS7 «Energía asequible y no contaminante» u ODS11 «Ciudades y comunidades sostenibles" donde se establecen medidas de movilidad urbana sostenible. Existen otra serie de ODS conexos con los aspectos medioambientales, como el ODS8 «Trabajo decente y crecimiento económico», íntimamente ligado con otros como ODS12 «Producción y consumo responsable» y el ODS9 «Industria, Innovación e Infraestructura», que requieren inversiones en eficiencia energética, economía circular, reutilización, reciclaje, saneamiento de agua, tratamiento y valorización de residuos urbanos, industriales y agropecuarios.

A nivel comunitario destaca la reciente publicación, del 11 de diciembre de 2019, de la Comunicación de la Comisión Europea «El Pacto Verde Europeo» ${ }^{4}$, que pone de manifiesto la gran inversión pública y movilización de recursos privados necesaria para posibilitar una transición ecológica sostenible, definiendo una hoja de ruta que incorpora un paquete de medidas sobre sectores como el energético (integración del mercado energético e infraestructuras inteligentes), el industrial (digitalización, plan de acción de economía circular, captura y $\triangleright$

\footnotetext{
3 De no lograr un mayor grado de ambición, la Agencia Internacional de Energías Renovables (IRENA 2019) estima que el incremento de la temperatura global podría detraer un $10 \%$ el crecimiento del PIB mundial en 2050.

4 https://eur-lex.europa.eu/resource.html?uri=cellar:b828d165-1c2211ea-8c1f-01aa75ed71a1.0004.02/DOC_1\&format=PDF
} 
utilización del carbono), el de la construcción, la movilidad, la biodiversidad o el agroalimentario $^{5}$. Así mismo, el pacto incluye el compromiso de la propuesta de una ley del clima europea durante el primer trimestre de 2020 con el fin de consagrar en la legislación el objetivo de alcanzar la neutralidad climática en 2050, coordinando la contribución de cada política de la Unión Europea a este fin y promoviendo que todos los sectores desempeñen de forma óptima el papel que les corresponde ${ }^{6}$.

A nivel nacional, la Agenda del Cambio constituye el principal eje vertebrador de la acción del Gobierno de España a largo plazo, hacia una economía sostenible e inclusiva en la que la transición ecológica juegue un papel esencial hacia la descarbonización plena de la economía española en 2050. Para su puesta en práctica se contemplan tres pilares fundamentales: el anteproyecto de Ley del Clima, el Plan Integrado de Energía y Clima 2021-2030 y la Estrategia de Transición Justa. Asimismo, en la Agenda del Cambio se recogen diversas iniciativas para impulsar la transición ecológica equitativa entre las que se enmarcan la regulación del autoconsumo de energía, el Plan de movilidad sostenible o el impulso a la economía circular entre otras.

\subsection{Inversiones necesarias para la consecución de los ODS}

En este contexto, la consecución de los ODS y la construcción de un modelo de crecimiento

\footnotetext{
5 Estos elementos están asimismo alineados con el documento de reflexión Para una Europa sostenible de aquí a 2030 (enero, 2019): $h$ ttps:// ec.europa.eu/commission/sites/beta-political/files/rp_sustainable_ europe_es_v2_web.pdf

6 En verano de 2020, la Comisión presentará un plan sometido a una evaluación de impacto que elevará el objetivo de reducción de las emisiones de gases de efecto invernadero de aquí a 2030 al $50 \%$, como mínimo, y hacia el $55 \%$ con respecto a los niveles de 1990.
}

económico sostenible requiere de una importante movilización de recursos ${ }^{7}$, entre otros, hacia proyectos de energías renovables, almacenamiento de $\mathrm{CO}_{2}$, eficiencia energética, movilidad sostenible, reforestación, reciclaje y reutilización de recursos, tratamiento de aguas y residuos sólidos urbanos, industriales y agropecuarios.

De acuerdo con el Programa de la ONU para el Desarrollo (UNDP), las necesidades sociales para erradicar la pobreza requieren una inversión de 66.000 millones de USD anuales, las inversiones en infraestructuras (agua, agricultura, telecomunicaciones, energía, transporte, inmobiliarias, industriales y forestales) se sitúan entre los 5 y 7 billones (trillones anglosajones) de USD, mientras que la provisión de instrumentos de mitigación del cambio climático, conservación de la biodiversidad o I+D requerirán otros tantos billones de dólares de inversión anuales.

El sistema energético tiene una especial relevancia dado que la producción y utilización de energía en todos los sectores económicos representa el grueso de las emisiones de gases de efecto invernadero (más del $75 \%$ en la $U^{8}{ }^{8}$. La Agencia Internacional de la Energía Renovable (IRENA) ${ }^{9}$ estima que un $60 \%$ de la reducción de emisiones para alcanzar los objetivos del Acuerdo de París podrían llevarse a cabo mediante un intenso proceso de electrificación de la economía en sectores como la movilidad sostenible o la edificación, con $\triangleright$

\footnotetext{
7 Financing the 2030 Agenda (UNDP 2018): https://www.undp.org/ content/undp/en/home/librarypage/poverty-reduction/2030-agenda/ financing-the-2030-agenda/

8 Comunicación El Pacto Verde Europeo.

9 IRENA (2019), Global Energy Transformation. A Roadmap to 2050 Según este estudio, los NDC actuales implican un nivel de emisiones de $\mathrm{CO}_{2}$ similar al actual en 2050, lo que podría implicar un aumento de 2,6 grados al final de la década, por encima de los Acuerdos de París. Este informe muestra que las emisiones deberían reducirse un 3,5\% anualmente hasta 2050 , con reducción siginificativa de aquellas vinculadas a la energía, que deberían alcanzar su máximo en 2020 y descender desde entonces.
} 


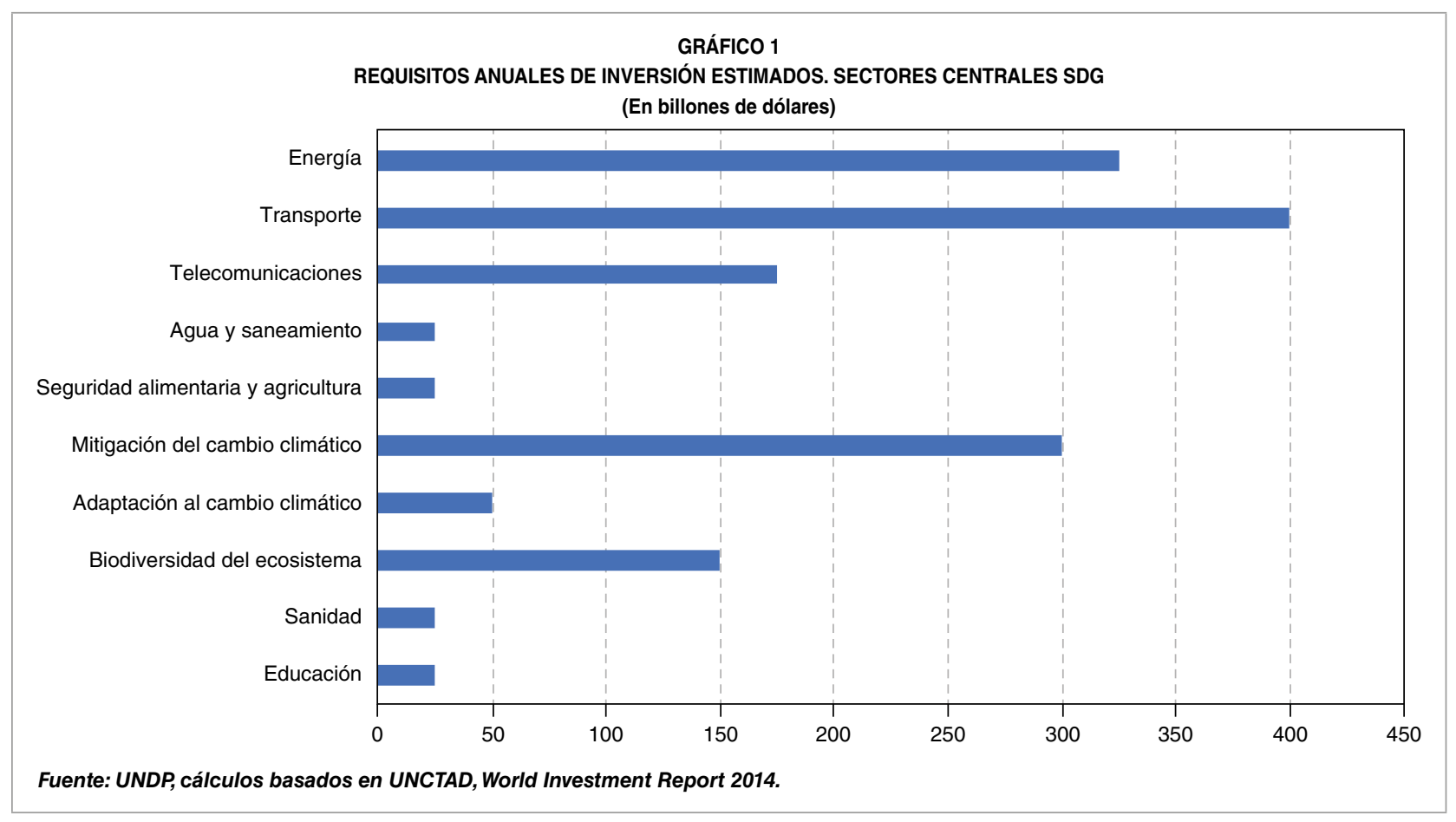

desarrollo de redes inteligentes, puntos de recarga y almacenamiento (baterías), acompañada de una amplia inversión en eficiencia energética y energías renovables, cuya dotación debería multiplicarse por seis hasta 2050 para proveer un $86 \%$ de la demanda energética final global $^{10}$. Esto se traduce en unas inversiones adicionales con respecto a los planes energéticos actuales de 15 billones de USD (en total la inversión en el sector energético debería alcanzar los 110 billones de USD en 2050).

En cuanto a la Unión Europea, la comunicación sobre el Pacto Verde Europeo estima que es necesaria una inversión anual adicional de 260.000 millones de euros, aproximadamente el $1,5 \%$ del PIB de $2018^{11}$ hasta 2030; y de cara a la neutralidad climática en 2050 la cifra

10 Aquellos sectores que presentan una mayor complejidad para ser electrificados, como el transporte por barco, aéreo o ciertos procesos industriales, deberán volverse más intensivos en el uso de biocombustibles. 11 Estas estimaciones son conservadoras, ya que no tienen en cuenta, por ejemplo, la inversión necesaria para la adaptación al cambio climático o para retos medioambientales, como la biodiversidad. También excluyen la inversión pública necesaria para dar respuesta a los costes sociales de la transición y los costes de la inacción. se situaría en 1,4 billones (trillones anglosajones) anuales desde 2031 hasta entonces.

En el caso de España, se estima que la inversión que va a movilizar el Plan Integrado de Energía y Clima 2021-203012 alcanzará los 23.600 millones de euros anuales. Por tanto, en ese periodo, la inversión total acumulada sería de 236.000 millones de euros en proyectos de eficiencia energética (37\%), energías renovables (42\%) y electrificación (18\%). Está previsto que el $80 \%$ de las inversiones serán realizadas por parte del sector privado y el $20 \%$ por el sector público.

\section{Las finanzas sostenibles, clave para la consecución de los ODS}

Teniendo en consideración las elevadas inversiones descritas, el sector financiero $D$

12 https://www.miteco.gob.es/es/cambio-climatico/participacion-
publica/notaexplicativadelborradordelpniec2021-2030_tcm30-487346.pdf 
debe jugar un papel clave generando incentivos y movilizando recursos en la escala y el plazo necesarios para facilitar la transición hacia un modelo de crecimiento sostenible bajo en emisiones. Así se reconoce en el artículo 2c de los Acuerdos de París, al indicar que es necesario «situar los flujos financieros en un nivel compatible con una trayectoria que conduzca a un desarrollo resiliente al clima y con bajas emisiones de gases de efecto invernadero' ${ }^{13}$.

También se ha puesto de manifiesto con el establecimiento, durante las Asambleas de Primavera del Banco Mundial-Fondo Monetario Internacional de 2019, de la Coalición de Ministros de Finanzas ${ }^{14}$ formada por 51 países, entre ellos España, cuya guía de acción se establece en los Principios de Helsinki ${ }^{15}$. Estos principios establecen las bases para actuar sobre el cambio climático compartiendo las mejores prácticas combinadas con el trabajo analítico para apoyar la acción política en torno a cuestiones como el precio del carbono, las políticas macroeconómicas y fiscales, así como la financiación climática a través del sector privado, bancos promocionales multilaterales, regionales y nacionales. En la reciente COP25 la Coalición ha lanzado el Plan de Acción de Santiago 2020 para alcanzar avances concretos en

13 Artículo 2c. de los Acuerdos de París (https://unfccc.int/sites/ default/files/spanish_paris_agreement.pdf).

14 http://pubdocs.worldbank.org/en/646831555088732759/FM-CoalitionBrochure-final-v3.pdf

15 Principios de Helsinki:

1. Align our policies and practices with the Paris Agreement commitments.

2. Share our experience and expertise with each other in order to provide mutual encouragement and promote collective understanding of policies and practices for climate action.

3. Work towards measures that result in effective carbon pricing.

4. Take climate change into account in macroeconomic policy, fiscal planning, budgeting, public investment management, and procurement practices.

5. Mobilize private sources of climate finance by facilitating investments and the development of a financial sector which supports climate mitigation and adaptation.

6. Engage actively in the domestic preparation and implementation of Nationally Determined Contributions (NDC) submitted under the Paris Agreement. cada uno de los principios. De forma específica, el principio 5 hace mención a las finanzas sostenibles y a la necesidad de continuar construyendo un sector financiero que apoye la inversión en proyectos de mitigación y adaptación climática.

En este contexto, los diversos agentes que operan en el sector financiero están trabajando de forma conjunta para establecer un marco de reglas e instrumentos diseñados de forma específica para facilitar la captación de recursos y su adecuada canalización hacia proyectos de inversión con impacto efectivo y medible.

Es lo que se trata de englobar dentro del concepto de «finanzas sostenibles» ${ }^{16}$, que supone la incorporación de principios ESG en las decisiones empresariales y estrategias de inversión. Las finanzas sostenibles implican a grandes rasgos la creación de nuevos productos financieros con criterios de sostenibilidad, la definición de metodologías, estándares y entes certificadores, la inclusión en la política de gestión del riesgo del impacto climático o el lanzamiento de iniciativas y compromisos conjuntos internacionales. Veremos a continuación en mayor detalle cada uno de ellos:

a. Productos financieros con criterios de sostenibilidad ${ }^{17}$. Productos de private equity, renta fija, préstamos o venture capital diseñados con el objetivo tanto de captación de recursos y su canalización hacia proyectos con impacto efectivo como de aumentar el compromiso de los clientes o prestatarios con la sostenibilidad. Entre $\triangleright$

16 Global Financial Stability Report: Lower for Longer (octubre de 2019, FMI): https://www.imf.org/en/Publications/GFSR/Issues/2019/10/01/ global-financial-stability-report-october-2019\#Chapter6

17 1) Equities. 2) Renta fija: fondos ESG en el mercado monetario, bonos verdes, bonos sociales, green mortgage-backed securities 3) Préstamos bancarios: préstamos verdes, préstamos sostenibles 4) Inversión alternativa: Green Real Estate Investment Trusts (REIT), private equity y venture capital. 
ellos, destacan los bonos verdes, que establecen un compromiso del emisor de informar sobre el uso e impacto de los fondos captados. Junto a estos, se encuentran igualmente cédulas y titulizaciones (green covered bonds), project finance para proyectos sostenibles, préstamos verdes 0 préstamos hipotecarios vinculados a la eficiencia energética de las viviendas.

b. Definición de estándares, certificadores, mediciones de impacto y reportes:

b.1. Taxonomía. Un aspecto clave para dotar de eficacia a estos productos financieros sostenibles es el establecimiento de una taxonomía homogénea que defina qué es una actividad sostenible y la medición de su impacto, evitando el green washing (declarar falsamente activos y fondos que no tienen impacto real vinculado a principios ESG) e induciendo la canalización de recursos hacia proyectos con efecto real sobre la reducción de emisiones. Precisamente el Plan de Acción de Finanzas Sostenibles ${ }^{18}$ de la CE (marzo, 2018), que cuenta con la participación de los Estados miembros y el seguimiento de ICO en coordinación con el Tesoro, tiene como uno de sus elementos principales la definición de una taxonomía para

18 Plan de Acción de Finanzas Sostenibles (https://ec.europa.eu/ commission/presscorner/detail/es/IP_18_1404).

- Establecer una taxonomía o lenguaje común para las finanzas sostenibles.

- Crear etiquetas de la UE para productos financieros verdes.

- Clarificar la obligación de inversores institucionales y gestores de activos de contemplar la sostenibilidad en su toma de decisiones.

- Obligar a empresas de seguros e inversión a ofrecer asesoramiento según las preferencias sobre sostenibilidad de sus clientes.

- Integrar la sostenibilidad en los requisitos prudenciales examinando la posible recalibración de los requisitos de capital aplicables a los bancos.

- Aumentar la transparencia de informes corporativos incluyendo información relacionada con el clima. actividades sostenibles ${ }^{19}$ en torno a tres tipologías: verdes (green), facilitadoras (enabling) y de transición (transition). Fue publicada por el Grupo de Expertos Técnicos (TEG) de la CE en junio de 2019, habiendo sido aprobada por Parlamento Europeo y el Consejo el 18 diciembre $2019^{20}$. Se espera que entre en vigor durante 2021.

b.2. Estándares y agentes certificadores. Junto a esto, es muy relevante la labor de los agentes certificadores que permitan constatar el uso efectivo de los recursos.

- Existen tres grandes tipos de certificación para los bonos verdes: Climate Bond Starndard (Climate Bond Initiative), Green Bond Principles (International Capital Market Association) y EU Green Bond Standards (Comisión Europea).

- En cuanto a los préstamos verdes, destacan los Green Loan Principles \& Sustainability ${ }^{21}$, publicado en marzo de 2019 por la Asociación de Mercados de Préstamos (Loan Market Association), decisiva para atraer a más participantes a este mercado más allá de la renta fija.

- En el caso del project finance, destaca una modalidad más amplia denominada Principios de Ecuador ${ }^{22}$, acordados por el sector financiero $\square$

\footnotetext{
19 https://ec.europa.eu/info/publications/sustainable-finance-tegtaxonomy_en

20 Aprobación del texto de compromiso sobre Regulación del Parlamento Europeo y el Consejo sobre el establecimiento de un marco para facilitar la inversión sostenible (https://data.consilium.europa.eu/doc/ document/ST-14970-2019-ADD-1/en/pdf).

21 https://www.Ima.eu.com/application/files/9115/4452/5458/741_ LM_Green_Loan_Principles_Booklet_V8.pdf

${ }_{22}$ https://equator-principles.com/wp-content/uploads/2019/11/TheEquator-Principles-November-2019.pdf
} 
en 2013 y reformado a finales de 2019 para la determinación, evaluación y gestión de los riesgos ambientales y sociales en la financiación de proyectos.

\section{c. Adaptación de la política de riesgos finan-} cieros para incluir la variable sostenibili$\mathrm{dad}^{23}$. Implica que el cambio climático se incorpore como una nueva variable en la función de riesgos financieros ${ }^{24}$. Puede contemplarse de acuerdo con el criterio de doble materialidad descrito en la propuesta de la Comisión Europea para la modificación de la Directiva de reporting no financiero (TEG [2019e], Technical Expert Group on Sustainanble Finance):

c.1. Impacto de la actividad de la empresa sobre el cambio climático. Medición de la huella de carbono de la cartera de inversión, con base en diversas metodologías como PCAF, «Partership for Carbon Accounting Financials», o PACTA, «Paris Agreement Capital Transition Assessment».

c.2. Impacto del cambio climático sobre la cuenta de resultados de la empresa, incluido en pruebas de resistencia o test de estrés climáticos. Este impacto puede estar asociado a:

\footnotetext{
23 Innovación Financiera para una Economía Sostenible. Andrés Alonso y José Manuel Marqués, Documentos Ocasionales, n.ำ1916, Servicio de Estudios del Banco de España (https://www.bde.es/f/webbde/ SES/Secciones/Publicaciones/PublicacionesSeriadas/Documentos Ocasionales/19/Fich/do1916.pdf).

24 En España, el anteproyecto de Ley de Cambio Climático y Transición Energética, presentado en febrero de 2019, establece un elemento novedoso en el ordenamiento jurídico nacional al considerar el riesgo climático, específicamente, como un riesgo financiero; se exige su integración para aquellas entidades cuyos valores estén admitidos a negociación en mercados regulados, entidades de crédito, entidades aseguradoras y reaseguradoras y diversas sociedades por razón de tamaño. Esto supone específicamente su identificación, medición y gestión, y a incluir dicha información anualmente en algún informe público de la entidad.
}

- Riesgos físicos, derivados de catástrofes naturales con impacto sobre la propiedad, tierra o infraestructuras.

- Riesgos transicionales, derivados de los ajustes de precios de activos en el contexto económico propio de la transición hacia una economía baja en carbono, dominado por un contexto cambiante en términos de marco regulatorio climático, progreso tecnológico y sentimiento de los agentes de mercado.

- Riesgos legales, derivados de la falta de cumplimiento de los estándares ESG o por demandas de las partes afectadas por los efectos negativos provocados por la empresa sobre el cambio climático.

\section{d. Iniciativas y asociaciones público-privadas:}

d.1. Principios de Banca Responsable ${ }^{25}$ a través de United Nations Environment Programme Finance Initiative (UNEP-FI), suscrito por 130 entidades de 47 países en septiembre de 2019 con el objetivo de facilitar el alineamiento de la estrategia de negocio de un banco con los ODS y el Acuerdo de París.

d.2. Compromiso Colectivo por la Acción Climática $^{26}$, firmado el 9 de diciembre de 2019 en el marco de la COP25 en Madrid. Coordinado por la Asociación Española de Banca (AEB) y CECA, y suscrito por una veintena de entidades, entre ellas ICO. Refleja el compromiso conjunto del sector bancario $D$

25 https://www.unepfi.org/banking/bankingprinciples/

26 https://www.aebanca.es/noticias/notas-de-prensa/los-bancosespanoles-acuerdan-reducir-la-huella-de-carbono-en-sus-balances-enlinea-con-el-acuerdo-de-paris/ 
español de reducir la huella de carbono en las carteras de crédito de los firmantes, de una forma susceptible de ser medida con criterios homologados internacionalmente y en línea con los objetivos marcados en el Acuerdo de París.

d.3. Principios de Inversión Responsable 27. Definidos en 2005 en el seno de la ONU, tienen como objetivo incentivar la incorporación de factores ambientales, sociales y de gobierno corporativo - y los riesgos que conllevan- en las decisiones de inversión y la gestión de activos. Hasta la fecha, 2.368 instituciones han firmado los Principios de Inversión Responsable.

d.4. Task Force on Climate-related Financial Disclosures (TCFD) ${ }^{28}$. Después de la COP21 en 2015 (Cumbre de París), el G20 encomendó a la TCFD analizar cómo incorporar la industria financiera al reto de la sostenibilidad y armonizar criterios y métricas al respecto. Las recomendaciones que la TCFD ha propuesto son un referente mundial. El informe definitivo ${ }^{29}$ destaca la necesidad de una mayor claridad en la medición del impacto climático en las compañías y en concreto recomienda el

27 Principios de Inversión Responsable (https://www.unpri.org/ download?ac=9764):

- Incorporaremos asuntos ASG en los análisis de inversión y en los procesos de toma de decisiones.

- Seremos propietarios activos e incorporaremos asuntos ASG en nuestras prácticas y políticas de propiedad.

- Procuraremos una divulgación adecuada de los asuntos ASG por parte de las entidades en las que invertimos.

- Promoveremos la aceptación e implementación de los principios en el sector de las inversiones.

- Trabajaremos de manera colaborativa para incrementar nuestra efectividad en la aplicación de los principios.

- Cada uno de nosotros presentará informes sobre nuestras actividades y progreso con respecto a la aplicación de los principios.

28 https://www.fsb-tcfd.org/

29 https://www.fsb-tcfd.org/publications/tcfd-2019-status-report/ establecimiento de análisis de escenarios que midan la resiliencia de sus estrategias. En esta línea, el Plan de Acción para las Finanzas Sostenibles de la European Banking Association ${ }^{30}$ (EBA) también recomienda el análisis de impacto por escenarios climáticos dentro del marco que se incluirá en los stress tests medioambientales.

d.5. Red-Network de Bancos Centrales y Supervisores para la Greening-Ecologización del Sistema Financiero (NGFS). Este Foro reúne a los bancos centrales y supervisores para abordar los riesgos financieros relacionados con el cambio climático, intercambiando experiencias, mejores prácticas, y contribuir a la gestión de riesgos climáticos en el sector financiero.

d.6. International Capital Market Association (ICMA). Representa a los principales participantes de los mercados de capital, incluidos los emisores, los inversores y la banca de inversión, mediante la definición de estándares aceptables para la industria. Son un marco de referencia válido de bonos verdes.

\subsection{Evolución del sector de finanzas sostenibles}

El movimiento mundial de la financiación sostenible ha llegado para quedarse. Está ganando terreno año tras año, recibiendo mayor atención por parte de todos los participantes del sector financiero. La conjunción de nuevos instrumentos, agentes, regulación y $\triangleright$

30 https://eba.europa.eu/eba-pushes-early-action-sustainablefinance 
compromisos a nivel internacional está favoreciendo el desarrollo de un sector aún muy joven e incipiente, si bien es cierto que aspectos abordados anteriormente —como la naturaleza voluntaria del reporting financiero y la falta de estandarización de los criterios para definir las actividades sostenibles - limitan y generan un cierto grado de fragmentación en el mercado tanto para emisores como para inversores.

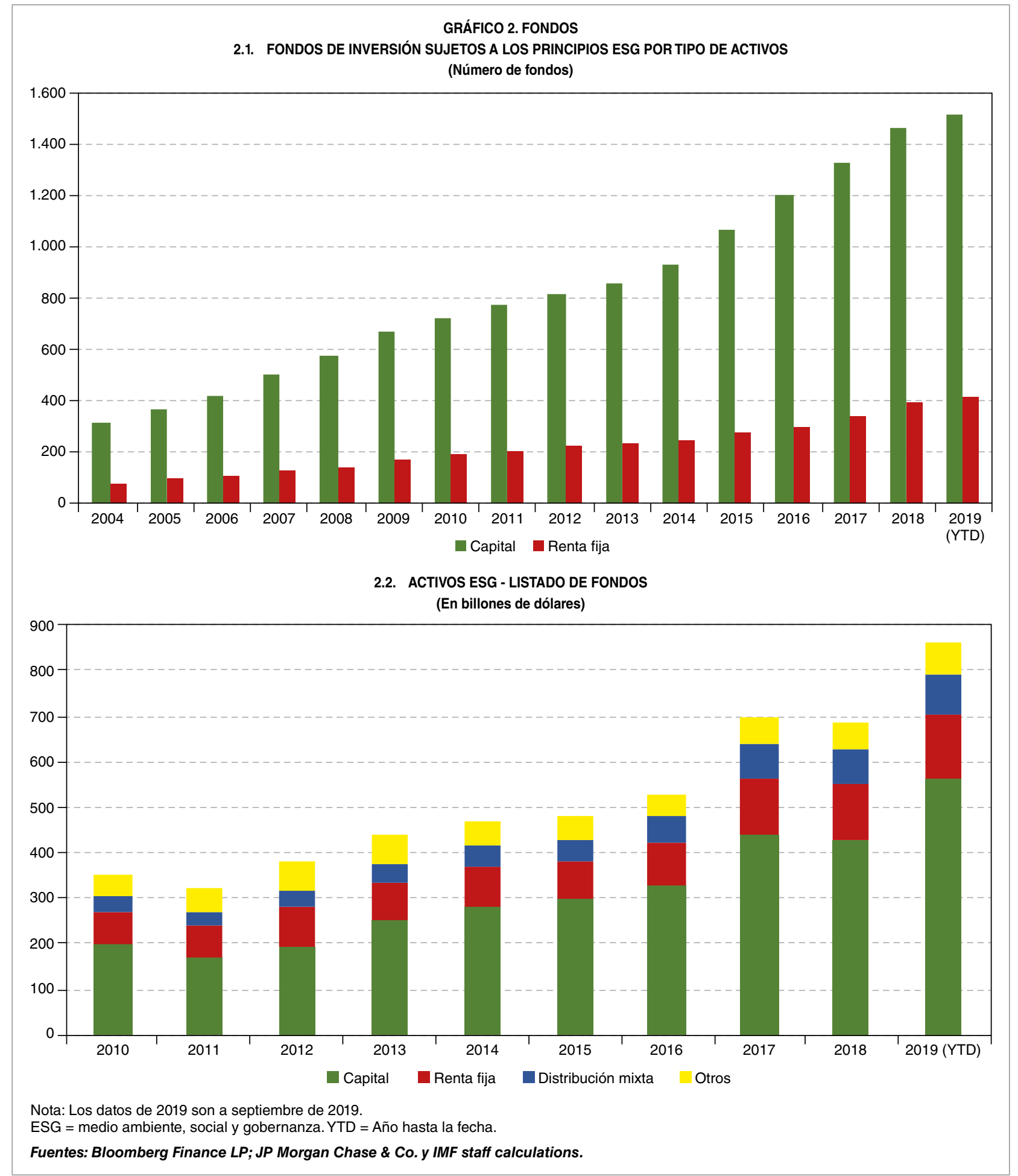


En tan solo diez años de existencia ha pasado de estar dominado originalmente por emisores como el Banco Mundial o el Banco Europeo de Inversores, y de estar concentrado en inversiones en capital (recursos propios) a contar con una amplia gama de emisores, inversores institucionales, empresas privadas, bancos y Gobiernos, con una mayor relevancia de la renta fija. La falta de estándares hace complicado establecer el tamaño total de los activos vinculados a principios ESG, oscilando entre los 3 billones de USD, según JP Morgan (2019), hasta los 31 billones de USD, según Global Sustainable Investment Alliance (2019).

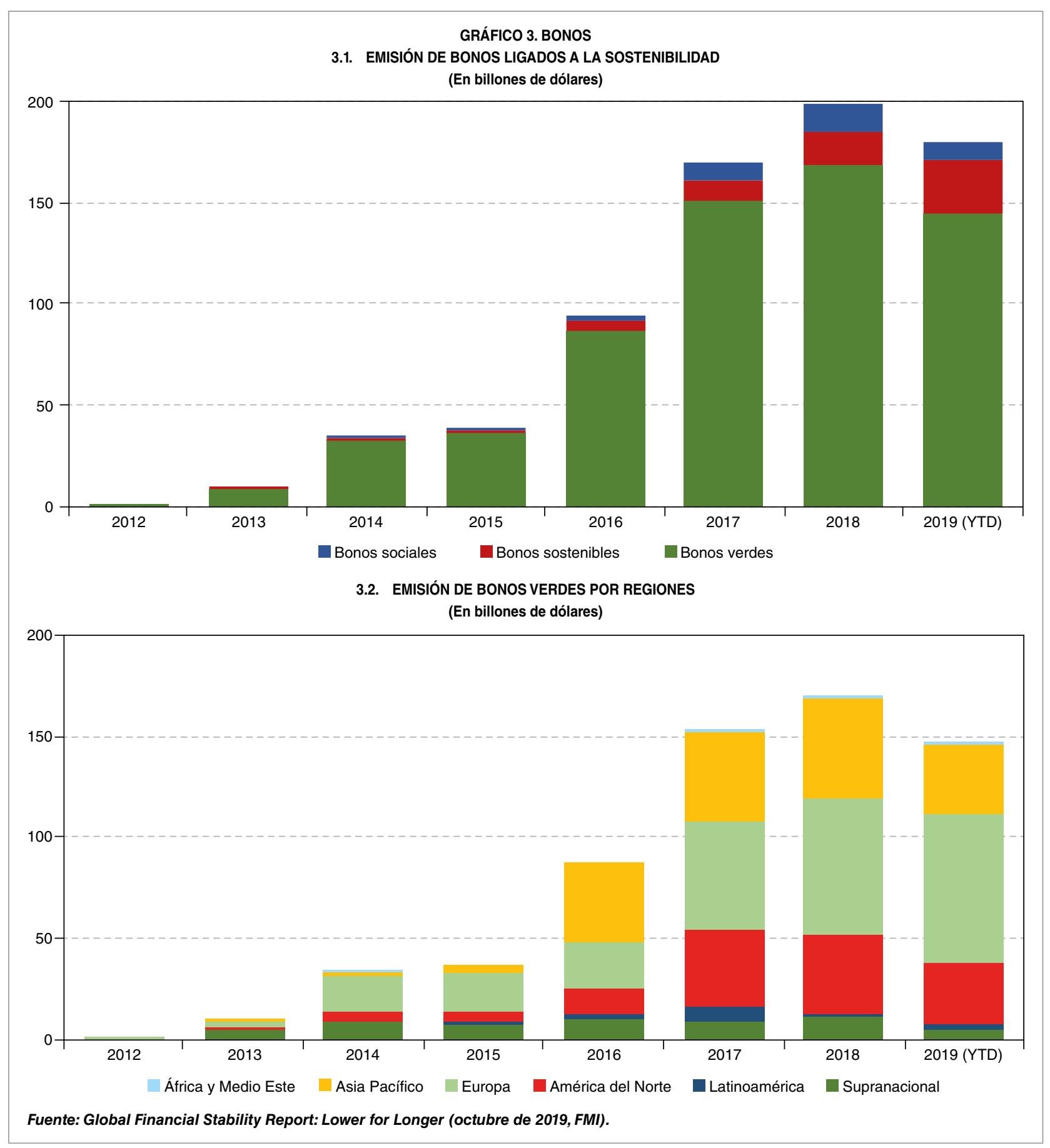


Los fondos de inversión sujetos a principios ESG ascienden a 850.000 millones de USD por valor de activos, lo que supone tan solo un $2 \%$ del total de fondos de inversión, pero la progresión es muy notable, siendo especialmente destacados los equity funds por valor de 560.000 millones de USD en $2019^{31}$.

En cuanto a mercado de bonos «etiquetados» (labelled), en especial los bonos verdes, las emisiones se ha multiplicado por seis entre 2015 y agosto de 2019, hasta alcanzar un stock actual de 590.000 millones de USD, debido especialmente a las emisiones procedentes de Europa y más recientemente de China. Para el conjunto de 2019, BBVA prevé que los mercados de capitales a nivel global batirán nuevamente un récord de emisión de bonos verdes, con 220.000 millones de dólares a nivel mundial.

En España, la cantidad total de bonos verdes emitidos alcanzó la cifra de 9.300 millones de euros en 2019 , el $12 \%$ del volumen total emitido de renta fija pública, según las estimaciones de Société Générale ${ }^{32}$. A nivel global, por lo general son bonos de alta calidad crediticia (investment grade), estando los emisores concentrados principalmente en el sector financiero, seguido del energético y estatal, y con menor relevancia del inmobiliario y transporte.

De forma conjunta, contando con emisiones de bonos y concesión de préstamos sostenibles, Bloomberg Finance LP estima que en el conjunto de 2019 se alcance una cifra total de financiación sostenible de 380.000 millones

\footnotetext{
31 Global Financial Stability Report: Lower for Longer (octubre de 2019, FMI)

32 https://www.europapress.es/economia/finanzas-00340/noticiaemisiones-bonos-espana-crecieron-137-2019-societe-generale20200123123815.html
}

de USD (en el gráfico se refleja para 2019 cifra del primer semestre $)^{33}$.

\section{Estrategia sostenible del Grupo ICO}

En la labor de impulsar los ODS y la construcción de un sector de finanzas sostenibles que posibilite su consecución, el ICO está teniendo un papel destacado y pionero como señalizador e impulsor de nuevos productos, estándares, políticas e iniciativas, haciendo un especial énfasis en las pymes.

Tomando como guía de acción a nivel global la Agenda 2030, a nivel nacional la Agenda del Cambio y a nivel comunitario el Pacto Verde Europeo, el Grupo ICO, en su triple faceta como banco público de financiación a la empresa, instrumento financiero de política económica y agente financiero del Estado, ha situado a través de su Reorientación Estratégica 2019-2021 la sostenibilidad como un eje transversal de actuación en sus diversas vertientes, medioambiental, social y de gobernanza (ESG), involucrando toda la organización y su actividad tanto en operaciones de pasivo, captando financiación en los mercados internacionales, como en su canalización hacia operaciones de activo, financiando a empresas y proyectos.

Los principios ESG rigen igualmente la política de responsabilidad social empresarial de ICO - tanto a nivel interno como externopara que sea una entidad integradora de los valores éticos, sociales y ambientales, $D$

33 Por otro lado, cabe destacar como referencia que en la COP25 celebrada en Madrid se ha duplicado el número de fondos de inversión que se han comprometido a que sus carteras sean neutras en emisiones tan pronto como sea posible, pasando de carteras que suman 2,4 billones de dólares durante la Cumbre del Clima de Nueva York a 4 billones en la COP25. Así mismo, el número de multinacionales comprometidas a ser neutras en carbono en 2050 se ha duplicado, pasando de 90 en la Cumbre del Clima de Nueva York a 177 en la COP25. En tamaño, estas empresas emplean a más de 5,8 millones de personas (https://www.lamoncloa.gob.es/serviciosde prensa/notasprensa/ecologica/Paginas/2019/151219cop25.aspx). 
transparente y comprometida socialmente, que aplica los principios de buen gobierno y los principios del Pacto Mundial de Naciones Unidas, de los que el instituto es firmante, velando por que sea reconocido en su actividad y en su relación con sus grupos de interés.

\subsection{EI ICO y los ODS}

El ICO focaliza su actividad en el cumplimiento del conjunto de los ODS, en especial aquellos que están más directamente relacionados con su misión: Crecimiento económico y generación de empleo de calidad (8), desarrollo de la industria, innovación e infraestructuras (9), procesos productivos y de consumo sostenibles (12).

En materia de sostenibilidad medioambiental, se presta especial atención a los objetivos relacionados con energía renovables (7) y el agua (6), ciudades sostenibles (11), la acción por el clima (13), océanos limpios (14), ecosistemas y entorno rural (15).

En materia de sostenibilidad social y gobernanza, el ICO se focaliza en los objetivos trabajo decente y crecimiento económico (8). Evidentemente, ICO, como banco público, promueve sus actuaciones desde la colaboración públicoprivada e institucional ODS (17). En su actividad, ICO, a través de la financiación a empresas españolas en su actividad nacional e internacional en terceros países, coadyuva al conjunto de ODS teniendo efectos positivos directos, indirectos o inducidos en muchos de ellos.

\subsection{La sostenibilidad como principio de gobernanza interna en el ICO}

Los principios ESG rigen la política de responsabilidad social corporativa a nivel interno en los procedimientos y organización del Grupo ICO, desde la elaboración de una Memoria Integrada de Sostenibilidad hasta las políticas internas de medición de la huella de carbono, gestión de recursos materiales, humanos, igualdad o prevención del blanqueo de capitales, entre otros.

a. La Memoria Integrada de Sostenibilidad del $\mathrm{ICO}^{34}$, publicada desde 2016 y alineada en su totalidad con los ODS desde 2019 (Memoria 2018), ha sido elaborada bajo los principios de transparencia, claridad e integridad, de acuerdo con los criterios del Global Reporting Intitiative (GRI), un estándar internacional para la comunicación de la información corporativa no financiera. La memoria, auditada por un verificador externo, contiene datos financieros y no financieros que permiten comparar $y$ evaluar el desempeño, ambiental, social y de buen gobierno (ESG), de esta Institución a los diferentes grupos de interés. Destacar a este respecto que en materia de transparencia y buen gobierno de las empresas públicas ICO ocupa el cuarto lugar en el ranking de Transparencia Internacional España (sobre 45 empresas públicas analizadas).

b. Sostenibilidad ambiental (ODS12, ODS13). El Grupo ICO cuenta con una política de gestión ambiental que pretende fomentar las mejores prácticas en su relación con grupos de interés: tanto con proveedores, estableciendo, cuando el objeto del contrato lo permita, requisitos ambientales y $\triangleright$

34 Memoria Integrada ICO 2018: https://www.ico.es/documents/19/ 1950386/Memoria+Integrada+2018/6a8571bc-c46a-42df-a6ff$26 d 6 c a d 2 f d 9 d$ 
sociales en las licitaciones ${ }^{35}$, como con empleados, promoviendo campañas para el uso eficiente de los recursos. Las magnitudes del año 2018 así lo reflejan:

b.1. Papel. $93 \%$ reciclado. Disminuye un $1,2 \%$ el consumo por empleado.

b.2. Eficiencia y ahorro energético. La intensidad energética disminuye un 3,9\% (Kwh/empleado).

b.3. Huella de carbono. Reducción de emisiones de gases de efecto invernadero directas e indirectas asociadas a un menor consumo eléctrico $\left(-19 \% \mathrm{Tm} \mathrm{CO}_{2}\right)$ y a una optimización de los desplazamientos del personal $\left(-51 \% \mathrm{Tm} \mathrm{CO} \mathrm{CO}_{2}\right.$ ).

b.4. Agua. Disminución del consumo por empleado del $22 \%$.

c. Sostenibilidad ambiental. Clientes y operaciones. El compromiso medioambiental del Grupo ICO exige plantear los riesgos ambientales de los proyectos como un parámetro más del análisis de los mismos. La aprobación de la taxonomía mencionada anteriormente implicará igualmente una adaptación del Instituto para medir adecuadamente el impacto sobre la sostenibilidad de su cartera de activo y de forma concreta a nivel climático la huella de carbono de los proyectos financiados.

d. Sostenibilidad social y gobernanza (ODS5, ODS8):

d.1. Igualdad de género (ODS5). ICO asegura la participación plena y efectiva de

35 En 2018, un $32 \%$ de las licitaciones se realizaron por el procedimiento de subasta, por lo que no procedía incluir en ellos criterios sociales o ambientales. De las licitaciones restantes, el 76,5\% incluía cláusulas sociales como criterios a tener en cuenta en caso de empate. En lo que respecta a cláusulas ambientales, un $17,6 \%$ de las licitaciones incluyeron requisitos ambientales como criterio de adjudicación. las mujeres y la igualdad de oportunidades de liderazgo, como refleja la aprobación en diciembre de 2019 de su II Plan de Igualdad ${ }^{36}$. El $61 \%$ de la plantilla está formada por mujeres, representando un $44 \%$ de los cargos directivos y mandos intermedios. En cuanto al Consejo General, está formado actualmente por un $40 \%$ de mujeres (4 sobre un total de 10).

d.2. Conciliación. EI ICO está certificado como empresa familiarmente responsable, dotando unas condiciones flexibles y dignas de trabajo (flexibilidad horaria, jornada partida, continua, reducida, teletrabajo).

d.3. Mejores prácticas financieras en diversas materias, incluida la prevención del blanqueo de capitales.

e. Educación financiera. El Grupo ICO, a través de la Fundación ICO, está involucrado en desarrollar la educación financiera de la sociedad en general y las pymes en particular, organizando conferencias, talleres y estudios. Actualmente se está llevando a cabo un estudio para identificar los retos y oportunidades que la economía circular ofrece a las pymes españolas.

f. Consultoría Europea de Sostenibilidad. ICO está desarrollando, en colaboración con la Comisión Europea a través del SRSS ${ }^{37}$, una consultoría para potenciar el Plan de Acción de Finanzas Sostenibles que impulse la sostenibilidad de manera global en toda la organización, teniendo en cuenta $\triangleright$

\footnotetext{
36 https://www.ico.es/documents/19/14629/II+PLAN+/GUALDAD+ 1CO+Diciembre+2019.pdf

37 Structural Reform Support Service. El concurso se ha adjudicado por la Comisión Europea a Deloitte.
} 
las iniciativas que ICO ya está llevando a cabo y siempre sobre la base de los estándares y requerimientos europeos en la materia, alineados con el Marco Financiero Plurianual de la UE 2021-2027.

\subsection{La responsabilidad social empresarial. EI ICO como impulsor de iniciativas sostenibles nacionales e internacionales}

Los principios ESG rigen la política de responsabilidad social empresarial a nivel externo de ICO, a través del trabajo conjunto con otras instituciones e iniciativas, así como su adhesión a diversos compromisos nacionales e internacionales de la industria financiera y el sector público vinculados a la sostenibilidad. Entre ellos podemos destacar los siguientes:

a. Red Española del Pacto Mundial de Naciones Unidas. ICO es socio desde 2005 y forma parte de su comité ejecutivo desde 2010.

b. Colaboración con la Alta Comisionada de la Agenda 2030. Destaca la plataforma \#ICOpymeODS ${ }^{38}$, desarrollada de forma conjunta entre ICO, Red Española del Pacto Mundial de Naciones Unidas y la Alta Comisionada para la Agenda 2030, dirigida al desarrollo de un tejido empresarial sostenible a través de la sensibilización a las pymes sobre las oportunidades que ofrece la consecución de los ODS y la importancia de alineamiento de sus estrategias con los mismos.

\footnotetext{
38 https://icopymeods.ico.es/\#/
}

c. Compromiso Colectivo por la Acción Climática $^{39}$, al que ya se ha hecho referencia anteriormente. Refleja el compromiso conjunto del sector bancario español de reducir la huella de carbono en las carteras de crédito de las entidades firmantes.

d. ICMA-Green Bond Principles ${ }^{40}$. ICO es socio de la Asociación de Mercados de Capitales Internacionales (ICMA, por sus siglas en inglés), una de las instituciones más activas internacionalmente en la definición de certificación para emisiones de bonos verdes. ICO ha participado en la grupo de trabajo que elaboró la guía de «Social Bonds Principles" y es miembro desde 2019 del Consejo Asesor del Comité Ejecutivo de los Principios de los Bonos Verdes ${ }^{41}$ y de los Principios de los Bonos Sociales ${ }^{42}$, siendo la única entidad pública española y el único Banco Nacional de Promoción europeo que participa en esta categoría del Consejo Asesor.

e. LMA-Green \& Sustainable Green Loan Principles $^{43}$, establecidos en 2018 por la Asociación de Mercado de Préstamos (LMA) para calificar operaciones de préstamo verde en torno a cuatro pilares básicos: asegurar el uso de los fondos, someterse a un riguroso proceso de evaluación y selección de proyectos, control en la gestión de los fondos y realizar un seguimiento hasta la $\triangleright$

\footnotetext{
39 https://www.aebanca.es/noticias/notas-de-prensa/ los-bancos-espanoles-acuerdan-reducir-la-huella-de-carbono-en-susbalances-en-linea-con-el-acuerdo-de-paris/

40 Green Bond Principles (ICMA, 2018): https://www.icmagroup.org/ green-social-and-sustainability-bonds/green-bond-principles-gbp/

41 https://www.icmagroup.org/green-social-and-sustainabilitybonds/green-bond-principles-gbp/

42 https://www.icmagroup.org/green-social-and-sustainabilitybonds/social-bond-principles-sbp/

43 https://www.Ima.eu.com/application/files/9115/4452/5458/741_ LM_Green_Loan_Principles_Booklet_V8.pdf
} 
finalización y puesta en marcha. ICO utiliza este estándar para calificar sus préstamos verdes $^{44}$.

\section{f. Asociación de los Principios de Ecuador.} ICO está adherido a los principios de Ecuador desde el año $2016^{45}$, habiéndolos incorporado a sus procesos internos de evaluación de impacto de proyectos. Este conjunto de principios internacionalmente reconocidos en el sector financiero tienen como objetivo definir un marco de gestión del riesgo para determinar, evaluar y gestionar los riesgos sociales y medioambientales vinculados a proyectos.

g. Forética ${ }^{46}$. ICO es socio de Forética desde 2005. En el 2018, ICO lideró en colaboración con Forética la puesta en marcha del Grupo de Acción de RSE en la Empresa pública ${ }^{47}$ para compartir conocimiento e integrar los ODS en la estrategia de las empresas públicas para que puedan ejercer de palanca de cambio y ser referente del resto de actores económicos y sociales. Actualmente el Grupo cuenta con más de 28 entidades públicas asociadas y publicó en 2018 la Guía práctica de contribución de las empresas públicas a la Agenda 2030. En materia de transparencia y buen gobierno el ICO ocupa el cuarto lugar en el ranking de Transparencia Internacional España sobre 45 entidades y empresas públicas, solo detrás de CDTI, Adif e Ingeniera y Economía de transporte.

\footnotetext{
44 https://www.ico.es/web/ico/notas-de-prensa/-/blogs/eendesan

45 https://www.ico.es/en/web/ico_en/equator-principles

46 https://foretica.org/

47 Adif, Aena, Aquavall, Canal Sur Radio y Televisión, CESCE,
} Corporación Empresarial Pública de Aragón, Correos, Emasesa, ENAIRE, Enresa, Extremadura Avante, Grupo ENUSA, Grupo Tragsa, ICEX España Exportación e Inversiones, ICO, INCIBE, INECO, INFORMA D\&B, ISDEFE, ITVASA, Metro de Madrid, Paradores, Renfe, RTVE y Valenciaport. Además, Agencia EFE, COFIDES y la Red Nacional Sanitaria de Responsabilidad Social participan en calidad de miembros observadores. h. SPAINSIF ${ }^{48}$. ICO es uno de los 73 asociados de esta plataforma constituida como una asociación sin fin de lucro cuya misión es fomentar la integración de los criterios ESG en las políticas de inversión mediante el diálogo entre la comunidad inversora, Administraciones públicas y diversos grupos sociales, contribuyendo al desarrollo sostenible, así como concienciar e impulsar cambios en los procesos de inversión en las empresas y la ciudadanía en general.

i. FINRESP (Centro para las Finanzas Responsables y Sostenibles ${ }^{49}$. ICO mantiene una estrecha colaboración con este centro impulsado por diversas asociaciones del sector $^{50}$ financiero, que nace con la vocación de atender las dificultades y necesidades que tiene el tejido empresarial y, en particular las pymes españolas, para contribuir positivamente a los compromisos de la Agenda 2030.

j. Foro de Bonos sostenibles ${ }^{51}$, organizado anualmente por ICO, habiendo celebrado su $\checkmark$ edición en junio de 2019 en Madrid, coincidiendo con el Día Mundial del Medioambiente. Así mismo, ICO promueve y participa activamente en numerosos foros internacionales relacionados con las finanzas e inversiones sostenibles. Durante 2019 cabe destacar el papel desarrollado por ICO en la COP25 como organizador de un panel sobre finanzas sostenibles y la participación en más de diez jornadas y encuentros en el marco de la cumbre. Además, asumió la $\triangleright$

48 https://www.spainsif.es/acerca-de-spainsif/miembros-asociados/

49 http://www.finresp.es/\#

50 AEB y CECA (bancos), UNACC (cooperativas de crédito), UNESPA (seguros), INVERCO (fondos de inversión y fondos de pensiones).

51 V Foro de Bonos Sostenibles de ICO: https://www.ico.es/en/web/ ico_en/gallery/ico-sb-forum 
organización en Madrid de la Asamblea anual de ALIDE, que integra a los bancos nacionales de promoción de América Latina, Europa y otros países relevantes.

k. Grupo de Expertos Sustainability Proofing de Invest EU. Participación en el grupo de trabajo de expertos a nivel europeo para la definición de la metodología y criterios que se utilizarán para asegurar la sostenibilidad en los proyectos financiados a través de InvestEU, vinculado al Programa Financiero Plurianual de la UE 2021-2027.

I. Grupo de Trabajo en el Plan Estratégico de Internacionalización de la Economía Española. ICO participa en el desarrollo del Plan de Acción Nacional de Empresas y
Derechos Humanos, cuyo objetivo es elaborar una guía para examinar la coherencia de las políticas de apoyo a la internacionalización empresarial y su alineación con los Principios Rectores de Derechos Humanos de Naciones Unidas.

\section{Sostenibilidad y la actividad de pasivo de ICO. Emisión de bonos sostenibles}

ICO, en su labor de captación de recursos en los mercados de deuda y capitales, está teniendo un papel muy relevante en la construcción del mercado de bonos sostenibles en España y Europa. A lo largo de los últimos cinco años, ICO ha realizado un total de siete $D$

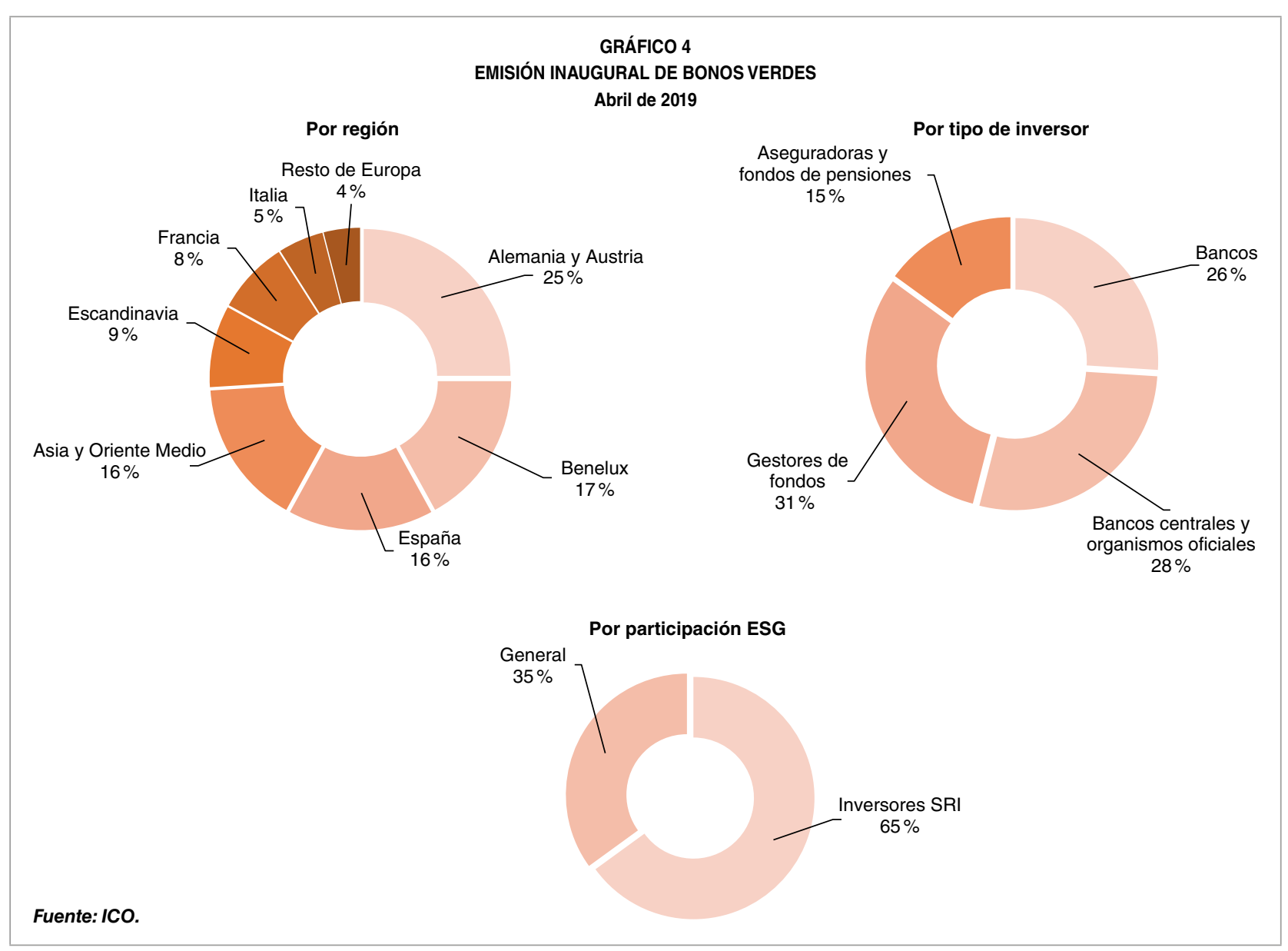


emisiones de bonos sostenibles ( 1 verde, 6 sociales) por valor de 3.550 millones de euros, de los que más de un $42 \%$ se han realizado durante los últimos doce meses ${ }^{52}$.

En 2019 lanzó la Plataforma de Bonos Verdes y la emisión inaugural de bonos verdes en abril por valor de 500 millones de euros. Una emisión exitosa, con la mayor ratio de cobertura en la historia de ICO (registrando una demanda de 3.400 millones de euros, seis veces superior al valor de emisión) y a un tipo muy competitivo, con el spread más estrecho sobre la referencia del Tesoro (Tesoro+7pb). El 65\% de los bonos se distribuyó entre inversores institucionales y financieros que operan de acuerdo a criterios de inversión medioambiental y sostenible, con una demanda del $84 \%$, procedente de inversores internacionales.

Los bonos verdes de ICO están nítidamente vinculados a la consecución del ODS13 Climate Action, permitiendo financiar proyectos relacionados con energías renovables, eficiencia energética, transporte limpio, prevención y control de la contaminación, gestión sostenible de los recursos naturales y uso de la tierra y gestión sostenible del agua. El programa también permitirá medir el impacto de los proyectos elegibles y su contribución a los objetivos de desarrollo sostenible, todo dentro del marco de los «Principios de bonos verdes» emitidos por la ICMA.

Para reafirmar su compromiso con el desarrollo del mercado de bonos sostenibles, a finales del mes de octubre de 2019 el ICO lanzó una nueva emisión de bonos sociales, de 500 millones de euros a tres años, nuevamente con una gran acogida entre los inversores, igualando el spread récord de la transacción de bonos verdes (Tesoro $+7 \mathrm{pb}$ ) de abril a tipos negativos

52 Octubre 2018-octubre 2019: tres emisiones de 500 millones de euros cada una.
$(-0,268 \%)$, y un valor suscrito cinco veces superior al emitido (2.500 millones). Desde 2015 el ICO ha realizado seis emisiones de bonos sociales por un importe superior a 3.050 millones de euros.

Este tipo de bonos tienen una clara vocación de inclusión y sostenibilidad social. En el marco de estas operaciones, ICO se compromete a financiar los proyectos de autónomos y pymes ubicados en regiones con un PIB per cápita inferior al promedio español. La emisión de bonos sociales realizada en noviembre de 2018 permitió financiar 7.177 proyectos de pymes, generando o manteniendo 61.800 empleos.

\section{Financiación ICO de inversiones empresariales y proyectos sostenibles}

Entre los principales retos para los emisores de bonos sostenibles se encuentran los costes de reporte y procedimientos de certificación externos, así como la dificultad de identificación de activos y proyectos elegibles, con impacto real y medible sobre la reducción de emisiones contaminantes $u$ otros objetivos sociales o de gobernanza.

En este contexto, la identificación y financiación de proyectos sostenibles a nivel global es uno de los objetivos prioritarios de la actividad de ICO, basado en la estrategia corporativa y guiado por los diversos compromisos e iniciativas a nivel nacional e internacional citados anteriormente.

\subsection{Financiación en el ámbito nacional}

Entre los sectores con impacto positivo sobre la sostenibilidad destacan la generación $\triangleright$ 
de energías renovables con fuentes eólica y fotovoltaica, solar, biomasa, incorporación de tecnologías que reduzcan las emisiones o tratamiento de residuos y aguas.

La labor de financiación de este tipo de proyectos se ha visto potenciada de manera significativa durante el año 2019, habiendo formalizado un número relevante de operaciones verdes o sostenibles por 800 millones de euros - con compañías como Endesa, Iberdrola, X-Elio, Adif y Grupo Ortiz, Acciona, Telefónica-, con un efecto tractor relevante entre pymes proveedoras y suministradoras de material, maquinaria y servicios de todo tipo tanto en España como en mercados exteriores. Como ejemplos de este tipo de operaciones podemos señalar el préstamo verde -concedido junto a $\mathrm{BEI}$ - a Iberdrola para la construcción de la mayor planta fotovoltaica en Europa (Núñez de Balboa), ubicada en Extremadura, o la financiación concedida al Grupo Ilunion que servirá para promover actuaciones de eficiencia energética y medioambiental del Plan de Inversiones 2018/2021 de la compañía.

\subsection{Financiación en el ámbito internacional}

En el ámbito de la financiación directa internacional, sobre una cartera de 1.450 millones de euros, 441 millones, más de un tercio (33\%), corresponden a 16 proyectos de energías renovables. Dado el carácter complementario y catalizador de recursos de otras instituciones que juega el ICO, su financiación tiene una gran capacidad de movilización de recursos, de modo que la inversión total en los proyectos descritos alcanzaría los 4.400 millones de euros.

La mayor parte de la financiación internacional directa de ICO se focaliza en Latinoamérica, donde se concentra el $45 \%$ de su portfolio. En Ios últimos años ICO ha financiado unos veinticinco proyectos en Latinoamérica por $860 \mathrm{mi}-$ llones de euros, movilizando inversiones por casi 10.198 millones de euros en todos los sectores de actividad. El resto de operaciones de financiación más relevantes se sitúa en Europa, con 141 millones de euros invertidos en Reino Unido y Portugal, sumando seis proyectos de energía fotovoltaica, plantas de biomasa y energy from waste con una inversión estimada movilizada de casi mil millones de euros.

Aún no existe una única metodóloga homogénea ni estándares internacionales para medir el impacto en reducción de emisiones y mitigación de inversiones en energías renovables y eficiencia energética, aunque se está avanzando en el ámbito de la UE con la taxonomía que se acaba de aprobar. A nivel global ${ }^{53}$, los proyectos de energías renovables financiados por ICO en su cartera internacional supondrían una nueva capacidad instalada de $1.600 \mathrm{MW}$, equivalente a 6 millones de toneladas de $\mathrm{CO}_{2}$ anuales.

En concreto, cabe destacar diversos ejemplos de proyectos internacionales con financiación de ICO a empresas españolas que están teniendo un impacto significativo de mitigación también en terceros países. La central fotovoltaica de Puerto Libertad (México) evita la emisión de casi un millón toneladas de $\mathrm{CO}_{2}$ al año, lo que correspondería al consumo aproximado de una ciudad de más de medio millón de habitantes en México. Por otro lado, la central de Cerro Dominador, en Chile, donde destaca el uso combinado fotovoltaico y termosolar, evitará la emisión de $\triangleright$

\footnotetext{
53 Las estimaciones que a continuación se detallan son preliminares $y$, simplificando, se refieren a las emisiones que se dejan de emitir por las energías renovables en relación con otras tecnologías que utilizan combustibles fósiles.
} 
880.000 toneladas de $\mathrm{CO}_{2}$ o lo que emiten 120.000 familias al año. La reducción de emisiones de $\mathrm{CO}_{2}$ facilitada por plantas de biomasa ${ }^{54}$ como Teeside (UK), con 299 MW de potencia, evita la emisión neta de entre 1,6 y 2,4 millones de toneladas de $\mathrm{CO}_{2}$ al año, en función de la tecnología que se tome como referencia, lo que supondría el consumo de 600.000 familias aproximadamente.

Además, es especialmente reseñable que entre el 15 y $20 \%$ de la financiación directa internacional del ICO ha sido concedida bajo los Principios de Ecuador descritos anteriormente. Es decir, son proyectos social y medioambientalmente sostenibles bajo estándares reconocidos y medibles internacionalmente. Se espera ir aumentando este porcentaje hasta el año 2030 , conforme a los acuerdos internacionales y recomendaciones que se vayan adoptando en la UE y la ONU.

Por otro lado, con el objetivo de contar con una mayor capilaridad a nivel internacional, ICO cuenta con diversos acuerdos de Canal Internacional con bancos multilaterales, regionales y locales públicos y privados, como CAF, BCIE, FONPLATA, COFIDE, BanBif, Sabadell o BBVA, localizados en América Latina, proporcionando financiación principalmente concentrada en proyectos promotores de la sostenibilidad y la inclusión en la región, desde renovables a TIC o transporte de infraestructuras que facilitan la movilidad baja en emisiones. En total, ICO cuenta con dieciséis acuerdos firmados con trece entidades con capacidad de movilizar 1.500 millones de euros.

54 No obstante cabe reconocer que las centrales de biomasa, según tecnología e inputs que emplee están siendo objeto de revisión a estos efectos, si bien en el caso del a UE se aplican los máximos estándares de eficiencia y reducción de emisiones.

\subsection{Private equity y venture capital, emprendimiento y empresas}

La construcción de un modelo de crecimiento sostenible requiere de talento y capacidad emprendedora. Los retos medioambientales presentes y futuros solo podrán afrontarse impulsando el espíritu emprendedor que favorezca el desarrollo de nuevos modelos de negocio, nuevos productos y soluciones. $Y$ en esta labor Axis, la empresa de capital de riesgo propiedad de ICO, ha acumulado experiencia apoyando al tejido empresarial español en sus primeras fases de desarrollo, impulsando la creación y el crecimiento de empresas en diversos sectores, incluyendo aquellos vinculados con la sostenibilidad. Para ello gestiona tres fondos: FOND-ICO Global (2.000 millones de euros), FOND-ICOpyme (250 millones de euros) y FOND-ICOInfraestructuras II (400 millones de euros), que invierten a lo largo de todas las fases del ciclo de inversión de las empresas y/o proyectos, desde las fases tempranas hasta start up, crecimiento y deuda. A nivel institucional, Axis participa en el grupo de promoción de la incorporación de España al Global Steering Group para la Inversión de Impacto.

a. FOND-ICO Global. En las últimas convocatorias de fondos se ha incorporado desde 2019 como criterio de evaluación —no limitativo- las inversiones en empresas de todos los sectores que incorporan actividades de innovación y digitalización, un factor que por su capacidad para dotar de eficiencia a la actividad empresarial y los procesos productivos tiene un impacto positivo indirecto sobre la sostenibilidad. A partir de las próximas convocatorias se incluirán igualmente la sostenibilidad medioambiental entre $\triangleright$ 
los criterios no limitativos. Cabe destacar que FondICO Global ha invertido en el primer fondo de Eficiencia Energética (SC Fondo de Eficiencia Energética) en España en 2013, y en el segundo con los mismos gestores (SC Fondo de Eficiencia Energética y Medio Ambiente II) en 2016.

b. Fond-ICOpyme. Iniciativa de sostenibilidad e impacto social, lanzada como novedad en 2019 por un importe objetivo de 50 millones de euros. La inversión está dirigida a entidades de capital privado que inviertan en compañías que desarrollen proyectos con un impacto social y/o ambiental y de economía circular significativo. Dentro de este marco, en abril de 2019, Axis firmó su primera participación en este fondo por importe de 5 millones de euros en Creas Impacto, el primer fondo institucional de inversión de impacto en España para apoyar a empresas sociales en fase de crecimiento.

c. FOND-ICOinfraestructuras II es un fondo de 400 millones de euros gestionado por Axis que invierte en infraestructuras sostenibles (transporte, infraestructuras sociales, energía y medio ambiente) en España y en el extranjero. Entre los proyectos más relevantes del primer fondo destaca un district heating de biomasa en Soria, Red de Calor de Soria, como un ejemplo emblemático de economía circular. También es reseñable la participación en múltiples proyectos de energías renovables, siendo el último Talasol, una planta fotovoltáica de $300 \mathrm{MW}$ que contribuye al liderazgo español en energías renovables. Se estima que los proyectos de infraestructura en cartera evitan la emisión de 287.000 toneladas de $\mathrm{CO}_{2}$.

\subsection{Participación en iniciativas de la UE: InvestEU, CEF, JICE y COI}

ICO trabaja a nivel de la UE para ofrecer una respuesta conjunta a los retos del cambio climático.

De acuerdo con la comunicación El Pacto Verde Europeo, la Comisión propone que un $25 \%$ del presupuesto europeo se dedique a los objetivos de dimensión climática y que al menos un $30 \%$ del programa o fondo InvestEU del próximo Programa Financiero Plurianual 20212027 contribuya a la lucha contra el cambio climático. El Programa InvestEU ${ }^{55}$ agrupará la multitud de programas financieros actualmente disponibles y ampliará el modelo del Plan de Inversiones para Europa del vigente programa financiero, con el objetivo cuantitativo último de promover inversiones por valor de EUR 650.000 millones, principalmente a través de garantías y blending.

En este contexto, el ICO está adoptando medidas para participar como implementing partner de InvestEU y eventualmente de otros instrumentos del presupuesto comunitario que incluirán un importante componente de acción climática. En concreto, el Instituto ha recibido el elegibility check (verificación de elegibilidad) para comenzar el proceso de auditoría previa a convertirse en implementing partner (socio implementador), que reunirá un amplio abanico de recursos financieros para promover proyectos sostenibles en Europa. El sustainability proofing (verificación de sostenibilidad) y el climate check (control de impacto climático) son de hecho dos requisitos críticos dentro del marco de InvestEU para garantizar que las inversiones cumplen con $\triangleright$

https://ec.europa.eu/commission/presscorner/detail/es/IP_18_ 
los objetivos definidos por la UE en materia medioambiental.

En este proceso, ICO ha sido acreditado en verano de 2019 por la Comisión Europea en el marco de la CEF-TBF (Connecting Europea Facility - CEF-, Transport Blending Facitiy -TBF-) para canalizar y gestionar fondos y subvenciones por valor de 198 millones de euros para proyectos sobre movilidad y transporte sostenible que puedan ser desarrollados por empresas europeas, incluidas las españolas, en España y en otros países de la UE. ICO, en este programa, colabora con el Ministerio de Transportes, Movilidad y Agenda Urbana y está proponiendo proyectos a desarrollar en concurrencia competitiva con otros Estados miembros.

La labor de identificación y financiación de proyectos sostenibles se lleva a cabo también de forma coordinada a nivel comunitario con otros bancos nacionales de promoción y de desarrollo, dada la responsabilidad de liderazgo y señalización en este campo y la necesidad de aunar esfuerzos y mejorar la colaboración entre las instituciones europeas.

En julio de 2019, en Luxemburgo, los cinco mayores bancos nacionales de promoción europeos (KFW de Alemania, CDP de Italia, CDC de Francia, BGK de Polonia e ICO), junto al $\mathrm{BEI}$, suscribieron la Iniciativa Conjunta para la Economía Circular (JICE por sus siglas en inglés) para apoyar el desarrollo y la ejecución de proyectos y programas de economía circular en la Unión Europea por valor de 10.000 millones de euros hasta 2023. El objetivo es evitar y eliminar los residuos, aumentar la eficiencia en el uso de los recursos y fomentar la innovación mediante la promoción de la circularidad en todos los sectores de la economía. En este ámbito, podemos destacar como proyecto de referencia la planta de red de calor de
Soria - mencionada anteriormente- que suministra calor y agua caliente a más de 16.000 habitantes en 8.000 hogares. Con una inversión de unos 20 millones de euros, ICO participa en el capital —siempre en proporción minoritaria- a través de FOND-ICOinfrastructuras. La cantidad de energía renovable generada es de unos $80 \mathrm{GWh} / a n ̃ o$, evitando la emisión de unas 28.000 t/año de $\mathrm{CO}_{2}$, usando recursos locales y generando empleo en la provincia

El proyecto Curtis, ejecutado por Greenalia, también es un buen referente en este ámbito. EI ICO participó junto con el BEI y otras entidades privadas en la financiación, por importe total de 125 millones, para la construcción de esta planta de combustión de biomasa forestal para la producción de energía eléctrica en la localidad de Curtis-Teixeiro (La Coruña, Galicia), de aproximadamente $50 \mathrm{MW}$ de potencia.

EI ICO dio un paso más en su estrategia de colaboración con otros bancos nacionales y multinacionales de promoción en iniciativas que contribuyan al desarrollo de proyectos sostenibles con su adhesión a la Clean Ocean Intiative, anunciada el 20 de octubre de 2019 en Washington, durante las Asambleas Anuales del BM/FMI. Esta iniciativa -promovida en 2018 por BEI, KFW y la Agencia Francesa de Desarrollo (AFD) - tiene como objetivo la implantación efectiva de un modelo sostenible que ayude a mitigar los efectos del cambio climático y luchar contra la polución en los océanos, mediante la financiación de proyectos que contribuyan a la gestión eficiente de los procesos de producción y reciclaje de residuos plásticos. En el marco de esta iniciativa, como ejemplo de financiación de ICO (a través de las Líneas ICO de Mediación con entidades financieras), destaca el proyecto de la empresa ECOALF, dedicada a recoger residuos marinos del fondo del mar, tratarlos y convertirlos en $\triangle$ 
hilo para fabricar ropa y accesorios. Para ello, la compañía trabaja con tres mil pescadores de cuarenta puertos, recogiendo y transformando 250 toneladas de residuos marinos al año y reciclando casi el $80 \%$ de los materiales que salen del mar.

\section{Conclusiones}

EI ICO, en su función como banco público, trabaja para aportar valor añadido a la financiación de las actividades e inversiones de las empresas, especialmente pymes, autónomos y emprendedores, tanto en España como en mercados internacionales, con el objetivo de promover el crecimiento económico sostenible y la generación de empleo en línea con las políticas públicas recogidas a nivel internacional en la Agenda 2030, el Pacto Verde Europeo y, reflejadas a nivel nacional, en la Agenda del Cambio.

El movimiento mundial en torno a la necesidad de alcanzar modelos de desarrollo y crecimiento basado en la sostenibilidad a través de inversiones y financiación sostenible ha llegado para quedarse, como se ha puesto de manifiesto en la reunión COP25 del pasado mes de diciembre en Madrid. La sostenibilidad constituye un interés común compartido por ICO: contribuir al logro del desarrollo de los diecisiete Objetivos de Desarrollo Sostenible. Estos objetivos han de alcanzarse con el mercado y no contra el mercado. Por ello, también cabe compartir la necesidad de promover y fomentar un mercado de finanzas e inversiones sostenibles en el que emisores e inversores participen de forma eficiente. Debe basarse en incentivos positivos y que generen valor añadido adicional mediante esquemas de financiación atractivos y a plazos más largos y periodos de carencia del principal, y atendiendo a todos los sectores de actividad promoviendo la adaptación y transición justa a modelos energéticos renovables, sostenibles, equitativos y eficientes.

Como parte de sector público, el ICO, en su Reorientación Estratégica 2019-2021, tiene una aproximación muy pragmática alineada con el Nuevo Marco Financiero Plurianual 2021-2027 de la UE, basada en la colaboración público-privada nacional e internacional para afrontar los retos o desafíos a largo plazo que impulsan los cambios estructurales de nuestra economía en torno a cuatro ejes transversales de aplicación a todos los sectores de la economía, de la industria y los servicios: 1) Transformación digital, innovación y competitividad. 2) Sostenibilidad: cambio climático y medioambiente; transición energética y ecológica; economía circular e infraestructuras sostenibles. 3) Financiación complementaria para pymes, para el emprendimiento y startups. 4) Crecimiento socialmente sostenible mediante la financiación de actividades que generen empleo y colaboración con iniciativas públicas y privadas relativas que fomenten la inclusión social.

ICO toma como referencia lo acordado por el Gobierno dentro del marco de los Objetivos de Desarrollo Sostenible 2030 a través de la Agenda del Cambio, una agenda donde la transición ecológica y su puesta en práctica a través de diversas iniciativas como el Plan Nacional de Energía y Clima o el proyecto de Plan Nacional de Economía Circular juegan un papel muy destacado, o la Transición Energética Justa.

La sostenibilidad es un reto que exige, pero también estimula, en la labor de búsqueda constante de nuevas soluciones, de creatividad, innovación y espíritu emprendedor. En este sentido, los operadores del sector financiero, y de forma muy especial ICO en su $\triangleright$ 
calidad de banco público, tienen una importante labor señalizando la importancia que reviste la sostenibilidad, así como en la definición de productos financieros que faciliten el desarrollo de la actividad emprendedora, inversora y comercial de la iniciativa privada en este ámbito, desde proyectos relacionados con energías renovables hasta la movilidad, pasando por el tratamiento de residuos, gestión de agua, recursos forestales y agrícolas. 